RESEARCH PAPER RP833

Part of Journal of Research of the National Bureau of Standards, Volume 15, October 1935

\title{
HEAT OF COMBUSTION OF ISOBUTANE
}

\author{
By Frederick D. Rossini
}

ABSTRACT

The data of the present investigation yield for the heat evolved in the combustion of gaseous isobutane in oxygen to form gaseous carbon dioxide and liquid water, at $25^{\circ} \mathrm{C}$ and a constant pressure of 1 atmosphere, the value $2871.06 \pm 0.53$ international kilojoules per mole. With the factor $1 / 4.1833$, this value becomes $686.31 \pm 0.13$ kilocalories per mole. The isobutane used was estimated to be of such purity that its heat of combustion would differ from that of an absolutely pure sample by less than 0.01 percent. The only previous determination of the heat of combustion of isobutane was that made by Thomsen over 50 years ago on some impure material. From these new data values are computed for the heat of formation of isobutane.

When combined with the previously reported data on the heat of combustion of normal butane, the present data yield for the reaction, $n-\mathrm{C}_{4} \mathrm{H}_{10}$ (gas) $=i$ so$\mathrm{C}_{4} \mathrm{H}_{10}$ (gas), at $25^{\circ} \mathrm{C}$ and 1 atmosphere, $\Delta H=-6.82 \pm 0.63$ kilojoules, or -1.63 \pm 0.15 kilocalories, per mole.

\section{CONTENTS}

I. Introduction $\ldots \ldots \ldots$

II. Units of energy, molecular weights, etc $\ldots$

III. Method, apparatus, and procedure

IV. Results of the present investigation _.

V. Data of previous investigations $\ldots \ldots$

VI. Conclusion_._.

VII. References

\section{INTRODUCTION}

This paper is a report on the calorimetric determination of the heat of combustion of isobutane, which investigation is part of the program of work being carried on by the thermochemical laboratory of the National Bureau of Standards on the accurate measurement of the heats of chemical reactions that are important to industry and science.

An accurate value for the heat of combustion of iosbutane will provide a reliable heating value for this gas when used as a fuel; will permit evaluation of its heat of formation to be used in thermodynamic calculations on the reactions of cracking, dehydrogenation, etc., in which isobutane may take part; when combined with the similar data on normal butane, will yield a reliable value for the energy of isomerism of the two butanes; when combined with appropriate other data, will yield values of the bond energies in the molecule; 
and, when combined with values of the entropy, will yield a reliable value for the free energy of formation.

There is extant in the literature only one report on the heat of combustion of isobutane, that published by Thomsen [1] ${ }^{1}$ in 1886 . The samples of isobutane that Thomsen had available were very impure, one sample having the empirical formula $\mathrm{C}_{4} \mathrm{H}_{9.75}$ instead of $\mathrm{C}_{4} \mathrm{H}_{10}$.

Because it is today possible to prepare isobutane of very high purity, and because the accuracy of present-day calorimetric measurements is considerably greater than was possible half a century ago, it was very desirable that a new determination of this thermochemical constant be made.

\section{UNITS OF ENERGY, MOLECULAR WEIGHTS, ETC.}

The unit of energy employed in this work, as in all previous publications from this laboratory, is the international joule, based upon standards of emf and resistance maintained at this Bureau. In order to report the results in calories, as well as in the fundamental unit of electrical energy, values in international joules are converted to a conventional defined calorie by means of the selected factor 1/4.1833. This is the same factor used in the previous conversions [2].

As in the previous work on the hydrocarbons, the thermal data obtained are independent of the atomic weight of carbon, 1 mole of isobutane being taken as equivalent to $5(18.0156) \mathrm{g}$ of water formed in the combustion [2].

\section{METHOD, APPARATUS, AND PROCEDURE}

The same calorimetric method, apparatus, and procedure were employed in these experiments as were used for the experiments on normal butane.

The sample of isobutane was obtained from the same source, prepared in the same manner, and tested for purity by the methods used on normal butane [2].

The data shown in table 1, obtained by Martin Shepherd, indicate the nature of the possible impurities. The amount of any impurity in mole fraction of the entire sample, is of the order of $1 / 10$ the value of $\Delta X_{B}$.

Six experiments on the determination of the ratio of carbon to hydrogen in the isobutane gave the following results: Average amount of isobutane used per experiment, 0.025 mole; average value of the ratio $10 \mathrm{C} / 4 \mathrm{H}, 1.00008$; average deviation from the mean, \pm 0.00008 ; maximum deviation from the mean, 0.00014. In obtaining the foregoing ratio, the masses of carbon dioxide and water were converted to moles by the use of the values 44.007 and 18.0156 , respectively, for the molecular weights ${ }^{2}[2,3]$.

From the manner of preparation of this sample of isobutane, and from the results of the foregoing tests, it appears that the purity of the isobutane was such that, per mole of water formed, its heat of combustion would differ from that of an absolutely pure sample by less than 0.01 percent. (See p. 739-740 of reference [2].)

1 The numbers in brackets here and elsewhere in the text refer to the references at the end of this paper. 2 The similar data on normal butane gave $1.00014 \pm 0.00012$, using 44.000 as the molecular weight of carbon dioxide. Using the value 44.007 , the data on normal butane yield $0.99998 \pm 0.00012$, for the ratio $10 \mathrm{C} / 4 \mathrm{H}$. See page 190 of reference [4]. 
TABLE 1.-Data on the purity of isobutane, as shown by measurement of the difference in the vapor pressures between the middle cut and the initial distillate and the final residue, respectively

\begin{tabular}{|c|c|c|c|c|c|}
\hline \multicolumn{3}{|c|}{ Initial distillate $^{1}$} & \multicolumn{3}{|c|}{ Final residue $^{1}$} \\
\cline { 1 - 3 } & $t$ & $\Delta X_{\mathrm{B}}$ & $\Delta p$ & $t$ & $\Delta X_{\mathrm{B}}$ \\
\hline $\begin{array}{c}\mathrm{mm} \mathrm{Hg} \\
13.08\end{array}$ & $\begin{array}{c}{ }^{\circ} \mathrm{C} \\
-11.2\end{array}$ & $\begin{array}{c}\text { Mole fraction } \\
\text { [0.008 propane }\end{array}$ & $\begin{array}{c}\mathrm{mm} \mathrm{Hg} \\
5.20\end{array}$ & $\begin{array}{c}{ }^{\circ} \mathrm{C} \\
-10.4\end{array}$ & $\begin{array}{c}\text { Mole fraction } \\
0.016 \text { normal butane }\end{array}$ \\
\hline
\end{tabular}

1 The amounts of the initial distillate and the final residue were respectively, less than $1 / 20$ of the entire sample. The value of $\Delta X_{\mathrm{B}}$ gives approximately the mole fraction of the given impurity in the initial distillate or the final residue, not in the entire sample.

The purity of the combustion reaction in the experiments on isobutane was examined as in the case of normal butane. No carbon monoxide was detected in the products of combustion.

The procedure for determining the amount of reaction in each calorimetric combustion experiment was exactly the same as in the experiments on normal butane, the amount of reaction being determined from the mass of water formed in the combustion. One mole $(18.0156 \mathrm{~g})$ of $\mathrm{H}_{2} \mathrm{O}$ was taken as equivalent to $1 / 5$ mole of $\mathrm{C}_{4} \mathrm{H}_{10}$.

The experiments made to determine the electrical-energy equivalent of the calorimeter system used for the combustion of isobutane are the same as those for normal butane, and the data are given in table 5 of reference [2]. The correction for "spark" energy was also the same as in the experiments on normal butane.

The calorimetric data of the combustion experiments with isobutane are given in table 2. The "error" of the mean value of the combustion experiments, computed as $\pm 2 \sqrt{\Sigma \Delta^{2} / n(n-1)}$, is \pm 0.013 percent.

TABLE 2.-Calorimetric results of the reaction experiments for isobutane

\begin{tabular}{|c|c|c|c|c|c|c|c|}
\hline \multicolumn{2}{|l|}{ Experiment } & $\Delta R$ & $k$ & $K$ & $U$ & $\Delta t_{\text {corr. }}$ & Avg temp. \\
\hline - & $\begin{array}{l}\text { Ohr } \\
0.40 \\
.41 \\
.41 \\
.40 \\
.40 \\
.41 \\
.40 \\
.40\end{array}$ & $\begin{array}{l}\text { Ohm } \\
0.409016 \\
.411889 \\
.410379 \\
.409650 \\
.409141 \\
.410224 \\
.409828 \\
.409531\end{array}$ & $\begin{array}{l}\min -1 \\
0.001936 \\
.001937 \\
.001926 \\
.001920 \\
.001921 \\
.001947 \\
.001945 \\
.001935\end{array}$ & $\begin{array}{l}\text { Ohm } \\
0.006180 \\
.006569 \\
.006319 \\
.006672 \\
.007059 \\
.006832 \\
.006138 \\
.006390\end{array}$ & $\begin{array}{l}\text { Ohm } \\
-0.000122 \\
-.000137 \\
-.000086 \\
-.000106 \\
-.000089 \\
-.000127 \\
-.000084 \\
-.000046\end{array}$ & $\begin{array}{l}{ }^{\circ} \mathrm{C} \\
3.99443 \\
4.01920 \\
4.00621 \\
3.99568 \\
3.98663 \\
3.99999 \\
4.00252 \\
3.99670\end{array}$ & $\begin{array}{l}{ }^{\circ} \mathrm{C} \\
25.00 \\
25.00 \\
25.00 \\
25.00 \\
25.00 \\
25.00 \\
25.00 \\
25.00\end{array}$ \\
\hline \multirow[t]{2}{*}{ Experiment } & $\begin{array}{l}\text { Electrical } \\
\text { energy } \\
\text { equivalent } \\
\text { of calorime- } \\
\text { ter system }^{1}\end{array}$ & $\begin{array}{l}\text { "Gas" } \\
\text { energy }\end{array}$ & $\begin{array}{l}\text { "Spark" } \\
\text { energy }\end{array}$ & $\begin{array}{l}\text { "Vapori- } \\
\text { zation" } \\
\text { energy }\end{array}$ & $\begin{array}{l}\text { Mass of } \\
\text { isobutane }\end{array}$ & $\begin{array}{l}\text { Heat of } \\
\text { combustion } \\
\text { at } 25^{\circ} \mathrm{C}\end{array}$ & $\begin{array}{l}\text { Deviation } \\
\text { from mean }\end{array}$ \\
\hline & $\begin{array}{r}\text { Int. joules } /{ }^{\circ} \mathrm{C} \\
15,237.1 \\
15,207.4 \\
15,223.1 \\
15,217.2 \\
15,251.6 \\
15,228.1 \\
15,238.7 \\
15,205.3\end{array}$ & $\begin{array}{r}\text { Joules } \\
9.5 \\
3.2 \\
.4 \\
-1.5 \\
2.0 \\
6.1 \\
2.4 \\
-3.1\end{array}$ & $\begin{array}{r}\text { Joules } \\
11.1 \\
12.5 \\
15.1 \\
17.7 \\
32.8 \\
19.0 \\
17.0 \\
13.8\end{array}$ & $\begin{array}{c}\text { Joules } \\
218.3 \\
233.2 \\
208.8 \\
219.0 \\
222.7 \\
207.6 \\
204.6 \\
219.0\end{array}$ & $\begin{array}{l}\text { Mole } \\
0.0212748 \\
.0213718 \\
.0213081 \\
.0212455 \\
.0212507 \\
.0212820 \\
.0213050 \\
.0212360\end{array}$ & $\begin{array}{c}\text { Int. kilo- } \\
\text { joules/mole } \\
2,871.01 \\
2,870.40 \\
2,871.26 \\
2,871.33 \\
2,870.23 \\
2,871.29 \\
2,871.78 \\
2,871.21\end{array}$ & $\begin{array}{r}\text { Kilojoules/ } \\
\text { mole } \\
-0.05 \\
-.66 \\
.20 \\
.27 \\
-.83 \\
.23 \\
.72 \\
.15\end{array}$ \\
\hline Mean... & & & & & & $2,871.06$ & \pm .39 \\
\hline
\end{tabular}

${ }^{1}$ Includes the heat capacity of one-half the mass of liquid water formed in the reaction. 


\section{RESULTS OF THE PRESENT INVESTIGATION}

The uncertainty in the final value obtained from the present data has been computed by taking the total percentage "error" as equal to $\pm \sqrt{e_{1}^{2}+e_{2}^{2}+e_{3}{ }^{2}}$, where $e_{1}$ is the percentage "error" of the mean value of the calorimetric experiments with electrical energy, $e_{2}$ that of the calorimetric combustion experiments, and $e_{3}$ is an "error" of 0.01 percent assumed in the determination of the amount of reaction, due to impurities and other causes.

The data of the present investigation yield for the heat evolved in the combustion of gaseous isobutane in oxygen to form gaseous carbon dioxide and liquid water, at $25^{\circ} \mathrm{C}$ and a constant pressure of 1 atmosphere, the value $2871.06 \pm 0.53$ international kilojoules per mole.

\section{DATA OF PREVIOUS INVESTIGATIONS}

The only previously reported determination of the heat of combustion of isobutane is that of Thomsen [1], made over 50 years ago. Thomsen performed three experiments on isobutane in his flame calorimeter at constant pressure and at an average temperature of about $18.5^{\circ} \mathrm{C}$. The first two experiments were made with a sample of isobutane having the empirical formula $\mathrm{C}_{4} \mathrm{H}_{9.748}$, and the third with a sample having the formula $\mathrm{C}_{4} \mathrm{H}_{9.899}$. Thomsen assumed that the impurity was butene, $\mathrm{C}_{4} \mathrm{H}_{8}$, and made a correction to his observed data to obtain a value for "pure" isobutane. He reported a value which, when converted to $25^{\circ} \mathrm{C}$ and the modern unit of energy, yields 685.6 kilocalories per mole. However, the writer has recomputed Thomsen's original calorimetric data, assigning a reasonable uncertainty and making correction for the impurity, unit of energy, etc., and obtains therefrom the value $686.2 \pm 1.6$ kilocalories per mole for the heat of combustion of isobutane at $25^{\circ} \mathrm{C}$ and a constant pressure of 1 atmosphere. While this indicates extraordinarily good agreement with the value from the present investigation, the accord must be somewhat fortuitous, since Thomsen's data on methane, ethane, and propane yield values not in accord, within the reasonable limits of error assigned to his work, with the values recently reported from this laboratory.

\section{CONCLUSION}

The present data yield for the reaction,

$$
\text { iso }-\mathrm{C}_{4} \mathrm{H}_{10} \text { (gas) }+\frac{13}{2} \mathrm{O}_{2} \text { (gas) }=4 \mathrm{CO}_{2} \text { (gas) }+5 \mathrm{H}_{2} \mathrm{O} \text { (liquid), }
$$

at $25^{\circ} \mathrm{C}$ and a constant pressure of 1 atmosphere, $\Delta H=-2,871.06$ \pm 0.53 international kilojoules per mole, or, using the factor $1 / 4.1833$, $\overrightarrow{\Delta H}=-686.31 \pm 0.13$ kilocalories per mole. 
Utilizing the values for the heats of formation of carbon dioxide and of water given in an earlier paper [3], the following values are obtained for the heat of formation of isobutane at $25^{\circ} \mathrm{C}$ :

$4 \mathrm{C}$ (c, $\beta$ graphite) $+5 \mathrm{H}_{2}$ (gas) $=i s o-\mathrm{C}_{4} \mathrm{H}_{10}$ (gas),

$\Delta H^{\circ}{ }_{298.1}=-32.20 \pm 0.43$ kilocalories per mole;

$4 \mathrm{C}$ (c, diamond) $+5 \mathrm{H}_{2}$ (gas) $=i s o-\mathrm{C}_{4} \mathrm{H}_{10}$ (gas),

$\Delta H^{\circ}{ }_{298.1}=-33.08 \pm 0.43$ kilocalories per mole.

Combination of the present value for the heat of combustion of isobutane with that previously reported for normal butane will yield a reliable value for the difference in the energies of formation of the two isomers. With no significant impurity in the reaction (see page 358), the reliability of the relatively small difference in the two values of the heats of combustion will be determined by the precision of the two values rather than by the absolute accuracy. The precision uncertainties of the calorimetric combustion experiments are, respectively, \pm 0.018 and \pm 0.013 percent, or \pm 0.52 and \pm 0.37 kilojoule per mole, for normal butane and isobutane. Taking the uncertainty in the difference in the two heats of combustion as the square root of the sum of the squares of the foregoing quantities, one obtains for the following reaction, at $25^{\circ} \mathrm{C}$ and 1 atmosphere,

$$
n-\mathrm{C}_{4} \mathrm{H}_{10} \text { (gas) }=i s o-\mathrm{C}_{4} \mathrm{H}_{10} \text { (gas), }
$$

$\Delta H_{298.1}=-6.82 \pm 0.64$ kilojoules, or $-1.63 \pm 0.15$ kilocalories, per mole. Since for the two isomers, at room temperature and a pressure of 1 atmosphere, the values of $P V$, and of $E(P=1)-E(P=0)$, are not significantly different, one can write for the above reaction $\Delta H^{\circ}{ }_{298.1}$ $=\Delta E^{\circ}{ }_{298.1}=-1.63 \pm 0.15$ kilocalories per mole. This value indicates that at $25^{\circ} \mathrm{C}$ the internal or intrinsic energy of isobutane is less than that of normal butane by $1.63 \pm 0.15$ kilocalories per mole. There is extant in the literature no value with which this can be compared. ${ }^{3}$

This new value for the heat of combustion of isobutane has also been utilized in conjunction with the previously reported data $[2,3]$ on methane, ethane, and propane, to deduce a fairly reliable value for the heat of combustion and of formation of tetramethylmethane (neopentane) [8].

\section{REFERENCES}

[1] Thomsen, Thermochemische Untersuchungen, IV, (Barth, Leipzig, 1886).

[2] Rossini, BS J. Research 12, 735 (1934) RP686.

[3] Rossini, J. Research NBS 13, 21 (1934) RP692.

[4] Rossini, J. Research NBS 13, 189 (1934) RP701.

[5] Roth and Macheleidt, unpublished. The numerical results appear in the Landolt-Börnstein-Roth-Scheel Tabellen, 5th ed., II, 1588. (Springer, Berlin, 1923.)

[6] Landolt-Börnstein-Roth-Scheel Tabellen, 5th ed., second supplement, p. 1634. (Springer, Berlin, 1931.)

[7] Private communication.

[8] Rossini, J. Chem. Phys. 3, 438 (1935).

Washington, July 1, 1935.

3 The values reported by Roth and Macheleidt [5] for the heats of combustion of gaseous normal pentane and isopentane (the difference of which would be expected to give a value in fair agreement with the above) have been withdrawn $[6,7]$. 